\title{
Red Light-emitting Diode Light Irradiation Improves Root and Leaf Formation in Difficult-to-propagate Protea cynaroides L. Plantlets In Vitro
}

\author{
How-Chiun Wu and Chun-Chih Lin ${ }^{1}$ \\ Department of Natural Biotechnology/Graduate Institute of Natural Healing \\ Sciences, Nanhua University, 55, Nanhua Road, Dalin Township, Chiayi 62249, \\ Taiwan, R.O.C.
}

Additional index words. 3,4-dihydroxybenzoic acid, blue light, caffeic acid, King Protea, red light

\begin{abstract}
The effects of light quality emitted by light-emitting diodes (LEDs) on the growth and morphogenesis, and concentrations of endogenous phenolic compounds of Protea cynaroides L. plantlets in vitro, were investigated. Plantlets were cultured under four light treatments: conventional fluorescent lamps (control), red LEDs $(630 \mathrm{~nm})$, blue LEDs (460 nm), and red + blue LEDs (1:1 photosynthetic photon flux). Four phenolic compounds extracted from the plantlets were analyzed: 3,4-dihydroxybenzoic acid, gallic acid, caffeic acid, and ferulic acid. The highest rooting percentage was observed in plantlets cultured under red LEDs (67\%) compared with 7\% under conventional white fluorescent light, $13 \%$ under blue LEDs, and $13 \%$ under red + blue LEDs. The highest number of roots per plantlet was also found under red LEDs, whereas a significantly lower number of roots per plantlet was obtained under the other light treatments. Furthermore, red light promoted the formation of new leaves in $P$. cynaroides plantlets. However, the highest leaf dry weight $(53.8 \mathrm{mg}$ per plantlet) was found in plantlets irradiated by the combination of red and blue LEDs. Phenolic analyses showed that the lowest concentrations of 3,4dihydroxybenzoic acid $\left(4.3 \mathrm{mg} \cdot \mathrm{g}^{-1}\right)$, gallic acid $\left(7.0 \mathrm{mg} \cdot \mathrm{g}^{-1}\right)$, and ferulic acid $\left(7.4 \mathrm{mg} \cdot \mathrm{g}^{-1}\right)$ were detected in plantlets exposed to red light, whereas those irradiated by white fluorescent light contained the highest concentration. A significant inverse correlation $(r=-0.419)$ was established between 3,4-dihydroxybenzoic acid and rooting percentage. Strong inverse correlations were also established between 3,4-dihydroxybenzoic acid and number of roots per plantlet $(r=-\mathbf{0 . 7 6 8})$ as well as between ferulic acid and number of roots per plantlet $(r=-\mathbf{0 . 7 3 2})$. These results indicate that the stimulation of root formation in $P$. cynaroides plantlets under red LEDs is the result of the low endogenous concentrations of 3,4-dihydroxybenzoic acid and ferulic acid.
\end{abstract}

Protea cynaroides L. (King Protea) is a slow-growing, semihardwood shrub (PattersonJones, 2000). It is one of the most important cut flowers belonging to the Proteaceae family, and it is notoriously known as a difficult-topropagate ornamental plant (Littlejohn et al., 2003; Thillerot et al., 2006). In particular, it has a poor physiological capacity for adventitious root formation. Conventional propagation methods used to propagate $P$. cynaroides are slow and inconsistent and typically have low success rates (Malan, 1992). Advances in the in vitro establishment of $P$. cynaroides nodal explants (Wu and du Toit, 2004) and apical buds (Thillerot et al., 2006) have been made. However, recurrent problems such as phenolic oxidation coupled with

Received for publication 19 June 2012. Accepted for publication 17 Aug. 2012.

Financial support in the form of a research grant (NSC 98-2313-B-343-001) from the National Science Council of Taiwan (R.O.C.) is gratefully acknowledged.

${ }^{1}$ To whom reprint requests should be addressed; e-mail benjasado@gmail.com. slow vegetative growth have resulted in limited success.

Light is an important stimulus for plant development and a key factor in morphogenesis (Okamoto et al., 1997). Responses of plants to light depend on the quantity (photon flux), quality (spectral quality), and duration (photoperiod) of the light source (Taiz and Zeiger, 1991). Cool white fluorescent lamps (FLs), which have a wide range of wavelengths from 350 to $750 \mathrm{~nm}$, are the most commonly used light source in plant tissue culture (Economou and Read, 1987). However, one of the disadvantages of fluorescent lamps is the difficulty of controlling light quality, which has been shown to have significant influences on plant morphogenesis. The use of LEDs as an alternative light source for in vitro propagation has drawn considerable interest. The advantages that LEDs have over FLs are their wavelength specificity, light intensity adjustability, low thermal energy output, and long lifespan (Bula et al., 1991; Hoenecke et al., 1992; Okamoto et al., 1997). Results of numerous studies showed significant improvements in plant growth and morphogenesis when exposed to light emitted by
LEDs. The effects of LEDs on morphogenesis of crops such as banana (Musa spp.) (Nhut et al., 2002), lettuce (Lactuca sativa) (Okamoto et al., 1996), pepper (Capsicum annuum) (Brown et al., 1995), potato (Solanum tuberosum) (Jao and Fang, 2004), spinach (Spinacia oleracea) (Yanagi and Okamoto, 1997), wheat (Triticum aestivum) (Goins et al., 1997), and calla lily (Zantedeschia jucunda) (Jao et al., 2005) have been well documented. Although research has shown that red and blue lights in particular have a significant influence on plant morphology, responses vary according to plant species. Appelgren (1991) observed that the exposure of Pelargonium (Pelargonium $\times$ hortorum cv. Penny Irene) plantlets to red light (660 $\mathrm{nm}$ ) in vitro significantly stimulated stem elongation, whereas blue light $(450 \mathrm{~nm})$ strongly inhibited stem elongation. In addition, findings by Poudel et al. (2008) showed that red LEDs increased rooting percentage and root numbers of grape (Vitis vinifera) explants. Furthermore, culturing Lilium hybrid explants under a combination of red and blue LEDs produced larger bulblets and a higher number of roots (Lian et al., 2002).

Phenolic compounds are known to play a role as endogenous promoters and inhibitors of adventitious root formation ( $\mathrm{Wu}$ et al., 2007b). In difficult-to-root species such as $P$. cynaroides, the presence and concentrations of phenolic compounds are particularly important. Besides the influence of light on plant morphogenesis, light irradiation has also been shown to affect the production of phenolic compounds and other secondary metabolites in plants. Early work by Tso et al. (1970) showed that the total phenolic content of tobacco (Nicotiana tabacum) plants, particularly chlorogenic acid, was increased when grown under far-red light. Furthermore, the phenolic content of buckwheat (Fagopyrum esculentum) leaves was significantly increased when the plants received a combination of red, green, and blue light (Hossen, 2007). In Saussurea medusa, a positive correlation was found between blue LEDs and the biosynthesis of flavonoids, whereas red LEDs inhibited flavonoid biosynthesis (Guo et al., 2007).

Research has shown that phenolic compounds are an important factor in the rooting of stem cuttings (Wu et al., 2007b). However, little is known about how light quality influences endogenous phenolic compound concentrations in $P$. cynaroides plantlets and their relationship with explant growth. This study was conducted to investigate the effects of light quality on the growth of $P$. cynaroides plantlets in vitro as well as to establish their relationship with endogenous phenolic compound concentrations and root formation.

\section{Materials and Methods}

Explant establishment through embryo culture. $P$. cynaroides seedlings were established using mature embryos excised from seeds. Surface sterilization of the seeds and 
embryo excision were done according to $\mathrm{Wu}$ et al. (2007a). After excision, the embryos were placed in an upright position into the growth medium in culture vessels. The growth medium contained half-strength Murashige and Skoog (MS) basal medium (Murashige and Skoog, 1962), sucrose (3\%) and agar $\left(9 \mathrm{~g} \cdot \mathrm{L}^{-1}\right)$. The $\mathrm{pH}$ of the medium was adjusted to 5.7 before autoclaving at $104 \mathrm{kPa}$ at $121{ }^{\circ} \mathrm{C}$ for $20 \mathrm{~min}$. The cultures were placed in a growth cabinet with the temperature adjusted to $21 \pm 2 / 12 \pm 2{ }^{\circ} \mathrm{C}(16 \mathrm{~h} / 8 \mathrm{~h})$. Illumination for embryo germination was provided by white FLs with a photoperiod of $16 \mathrm{~h}$ light $/ 8 \mathrm{~h}$ dark. After $30 \mathrm{~d}$, germinated seedlings with two true leaves were collected.

Explant and light treatments. Plantlets (seedlings with cotyledons and radicle removed) were laid horizontally on growth media in petri dishes. The petri dishes containing the plantlets were positioned vertically in an upright position on transparent plastic stands. The plantlets were cultured in medium containing full-strength MS medium without growth regulators but supplemented with sucrose $(3 \%)$ and agar $\left(9 \mathrm{~g} \cdot \mathrm{L}^{-1}\right)$. Five light treatments were used: cool white FLs (control), red $(630 \mathrm{~nm})$ LEDs, blue $(460 \mathrm{~nm})$ LEDs, and red + blue $(\mathrm{R}+\mathrm{B})$ LEDs [1:1 photosynthetic photon flux $(P P F)]$. The LEDs were purchased from Ryh Dah Inc. (Taiwan). The wavelengths of the LEDs were confirmed using a spectroradiometer (International Light Technologies; ILT900) (Fig. 1). Customized LED lighting systems were constructed with aluminum boxes (length, $50 \mathrm{~cm}$; width, $50 \mathrm{~cm}$; height, $25 \mathrm{~cm}$ ) and equipped with red, blue, or a combination of red and blue LEDs; a temperature sensor; a timer; and two fans. Three hundred LEDs were installed ( $2 \mathrm{~cm}$ apart) on the cover of each lighting system. Explants in petri dishes were incubated in the lighting systems, which were placed in a growth room. In all treatments, the photoperiod and temperature were adjusted to $16 \mathrm{~h} / 8 \mathrm{~h}$ and $25 \pm 2{ }^{\circ} \mathrm{C}$, respectively. The $P P F$ for all the light treatments was adjusted to $50 \mu \mathrm{mol} \cdot \mathrm{m}^{-2} \cdot \mathrm{s}^{-1}$. The $P P F$ was measured (LI-1800; LI-COR Inc.) at explant height.

Analysis of phenolic compounds. Shoots of plantlets that were cultured under different light sources were freeze-dried and ground into powder. An aliquot of the powder was weighed and the phenolic compounds were extracted in methanol $(1: 5 \mathrm{w} / \mathrm{v})$ overnight, after which the samples were evaporated to dryness. The dried samples were prepared in deionized water and analysis was performed with a high-performance liquid chromatography (HPLC) system (Hitachi L-2130 pump and a LiChroCART column packed with Purospher STAR RP-18e resin). Elution was performed in a stepwise gradient with a water (pH 2.6 adjusted with $\mathrm{H}_{3} \mathrm{PO}_{4}$ )/acetonitrile (ACN) volumetric ratio of $0 \mathrm{~min}, 7 \% \mathrm{ACN}$; 0 to $20 \mathrm{~min}, 20 \% \mathrm{ACN}$; 20 to $28 \mathrm{~min}, 23 \%$ $\mathrm{ACN}$; 28 to $40 \mathrm{~min}, 27 \%, \mathrm{ACN}$; 40 to $45 \mathrm{~min}$, $29 \%$, ACN; and 45 to $47 \mathrm{~min}, 33 \%$, ACN. The flow rate was $1 \mathrm{~mL} \cdot \mathrm{min}^{-1}$, and the injection volume was $20 \mu \mathrm{L}$. The separated compounds (including 3,4-dihydroxybenzoic, gallic, caffeic, and ferulic acids) were directly monitored at $270 \mathrm{~nm}$ by an ultraviolet spectrophotometer (Hitachi L2400) coupled in the HPLC analyzing system and then determined by a calibration curve prepared from standard solutions. Each determination was repeated three times. Results presented in this article are the average values, expressed in $\mathrm{mg} \cdot \mathrm{g}^{-1}$.

Statistical analysis. Three plantlets per petri dish were used with 15 replications per treatment. Data for rooting percentage, number of roots, number of leaves, leaf dry weight, and shoot dry weight were collected. The rooting percentage for the plantlets was obtained by first determining the number of rooted plantlets per petri dish. The total number of petri dishes with rooted plantlets per treatment was then calculated and expressed as

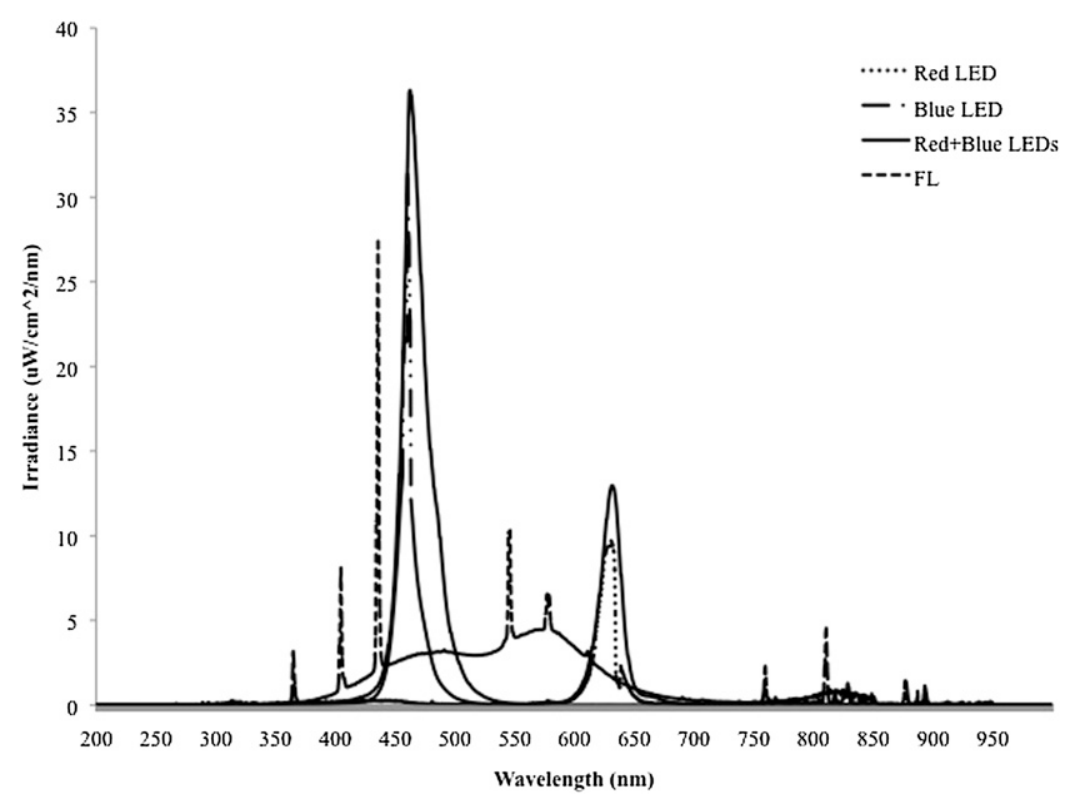

Fig. 1. Spectral distributions of light-emitting diodes (LEDs) and fluorescent lamp (FL).

Table 1. Effects of different light sources on root formation and vegetative growth of $P$. cynaroides plantlets after $45 \mathrm{~d}$ in culture.

\begin{tabular}{lccccc}
\hline Treatment & $\begin{array}{c}\text { Rooting } \\
(\%)\end{array}$ & $\begin{array}{c}\text { Roots/ } \\
\text { plantlet (no.) }\end{array}$ & $\begin{array}{c}\text { Leaves/ } \\
\text { plantlet (no.) }\end{array}$ & $\begin{array}{c}\text { Leaf dry } \\
\text { wt (mg/plantlet) }\end{array}$ & $\begin{array}{c}\text { Shoot dry } \\
\text { wt (mg/plantlet) }\end{array}$ \\
\hline FL & $6.7 \mathrm{~b}^{\mathrm{z}}$ & $1.0 \mathrm{~b}^{\mathrm{x}}$ & $5.6 \mathrm{~d}$ & $29.0 \mathrm{~b}$ & $64.8 \mathrm{a}$ \\
Red LED & $66.7 \mathrm{a}$ & $2.6 \mathrm{a}$ & $13.8 \mathrm{a}$ & $40.5 \mathrm{~b}$ & $58.1 \mathrm{a}$ \\
Blue LED & $13.3 \mathrm{~b}$ & $1.0 \mathrm{~b}$ & $11.7 \mathrm{~b}$ & $37.0 \mathrm{~b}$ & $55.6 \mathrm{a}$ \\
Red + blue LED & $13.3 \mathrm{~b}$ & $1.0 \mathrm{~b}$ & $9.5 \mathrm{c}$ & $53.8 \mathrm{a}$ & $63.8 \mathrm{a}$ \\
\hline
\end{tabular}

${ }^{\mathrm{z}}$ White fluorescent lamp.

${ }^{y}$ Percentages in the same column with different letters are significantly different (chi square at $P<0.05$ ). ${ }^{x}$ Means in the same column with different letters are significantly different (Duncan's multiple range test at $P<0.05)$.

LED $=$ light-emitting diode.

Table 2. Endogenous concentrations of phenolic compounds $\left(\mathrm{mg} \cdot \mathrm{g}^{-1}\right)$ in $P$. cynaroides plantlets grown under different light sources after $45 \mathrm{~d}$ in culture.

\begin{tabular}{lcccc}
\hline Treatment & $\begin{array}{c}\text { 3,4-Dihydroxybenzoic } \\
\text { acid }\left(\mathrm{mg} \cdot \mathrm{g}^{-1}\right)\end{array}$ & $\begin{array}{c}\text { Gallic } \\
\text { acid }\left(\mathrm{mg} \cdot \mathrm{g}^{-1}\right)\end{array}$ & $\begin{array}{c}\text { Caffeic } \\
\text { acid }\left(\mathrm{mg} \cdot \mathrm{g}^{-1}\right)\end{array}$ & $\begin{array}{c}\text { Ferulic } \\
\text { acid }\left(\mathrm{mg} \cdot \mathrm{g}^{-1}\right)\end{array}$ \\
\hline FL & $8.4 \mathrm{a}^{\mathrm{y}}$ & $14.6 \mathrm{a}$ & $15.9 \mathrm{a}$ & $9.7 \mathrm{a}$ \\
Red LED & $4.3 \mathrm{c}$ & $7.0 \mathrm{c}$ & $8.4 \mathrm{bc}$ & $7.4 \mathrm{c}$ \\
Blue LED & $6.0 \mathrm{~b}$ & $8.0 \mathrm{~b}$ & $8.0 \mathrm{c}$ & $8.2 \mathrm{~b}$ \\
Red + blue LED & $6.1 \mathrm{~b}$ & $7.9 \mathrm{~b}$ & $9.0 \mathrm{~b}$ & $8.7 \mathrm{~b}$ \\
\hline
\end{tabular}

${ }^{2}$ White fluorescent lamp.

${ }^{y}$ Means in the same column with different letters are significantly different (Duncan's multiple range test at $P<0.05$ )

$\mathrm{LED}=$ light-emitting diode. 
fluorescent light (6.7\%), blue LEDs (13.3\%) and red + blue LEDs (13.3\%) (Table 1). Furthermore, plantlets irradiated by red LEDs produced a significantly higher number of roots compared with the other light treatments (Tables 1 and 4). Similar results were reported in anthurium (Anthurium andreanum) (Budiarto, 2010), cotton (Gossypium hirutum) (Li et al., 2010), and chrysanthemum (Chrysanthemum morifolium) (Kurilčik et al., 2008), where red LEDs were also found to stimulate root formation. In addition, results showed that compared with conventional white fluorescent light, irradiation by LEDs significantly improved the formation of new leaves on $P$. cynaroides plantlets irrespective of the light quality. Moreover, these results revealed that plantlets grown under red LEDs in particular produced a significantly higher number of new leaves than any of the other LED treatments. However, the leaf dry weight of plantlets irradiated by the combination of red and blue LEDs was significantly higher than those grown under the other light treatments (Table 1). The stimulatory effect of red + blue LEDs on leaf growth is similar to those reported in chrysanthemum (Kim et al., 2004), Doritaenopsis (Shin et al., 2008), and strawberry (Fragaria $\times$ ananassa cv. Akihime) (Nhut et al., 2003). Although leaf area was not measured in this study, it is probable that the higher leaf dry weight was the result of larger leaves produced by plantlets in this treatment. According to Goins et al. (1997), the enhancement of growth and development of leaves by a combination of red and blue LEDs is attributed to their spectral energy distribution being consistent with that of chlorophyll absorption, and as a result, the net photosynthetic rate is increased. In addition, the spectral energy ratio between red and blue LEDs has been acknowledged to be of great importance in vegetative growth of plants (Okamoto et al., 1997). The presence of at least $10 \%$ blue light has been found to be beneficial to plantlet growth, whereas no differences were observed at lower percentages. It was therefore suggested that there is a minimum threshold level for blue light for optimal development under a red-based light source (Nhut and Nam, 2010). Although only a single ratio (1:1) was tested in this study, the results indicated that it is suitable for promoting the leaf growth of $P$. cynaroides plantlets.

Endogenous concentration of phenolic compounds. The lowest concentrations of 3,4-dihydroxybenzoic acid, gallic acid, and ferulic acid were found in plantlets irradiated by red LEDs, which were significantly lower than other light treatments (Tables 2 and 5). Although no previous information is available on the effects of light quality on these phenolic compounds, similar results have been reported for other phenolics under red light. Guo et al. (2007) showed that flavonoid biosynthesis in Saussurea medusa callus cultures was inhibited by red light irradiation. Similarly, leaves of Ocimum basilicum (Shoji et al., 2011) irradiated by red light were found to contain lower concentrations of chicoric acid. Total phenol content has also been shown to be lower in wheatgrass (Urbonaviciute et al., 2009a) and green barley leaves (Urbonaviciute et al., 2009b) irradiated by red LEDs. These results indicate that red light inhibits the accumulation of phenolic compounds and, in our case, 3,4-dihydroxybenzoic acid, gallic acid, and ferulic acid in particular. Furthermore, analysis of the results between phenolic compounds and root growth showed a significant inverse correlation between 3,4dihydroxybenzoic acid and rooting percentage [Pearson's coefficient $(r)=-0.419$ ] (Table 3 ). In addition, strong inverse correlations were also found between 3,4dihydroxybenzoic acid and the number of roots formed $(r=-0.768)$ as well as between ferulic acid and the number of roots formed $(r=-0.732)$ (Table 3$)$. The inverse correlation between 3,4-dihydroxybenzoic acid and root number is in agreement with the results of a dose-response bioassay (Wu et al., 2007b), which showed that 3,4-dihydroxybenzoic acid at low concentration stimulates root growth of lettuce seedlings. Subsequent investigations of the same study showed that rooted $P$. cynaroides cuttings contained low endogenous concentrations of 3,4-dihydroxybenzoic acid. Similar findings were reported by Mucciarelli et al. (2000), in which low concentrations of 3,4-dihydroxybenzoic acid were found to possess auxin-like activities by stimulating tissue dedifferentiation and significantly increased root formation in tobacco callus. It has been suggested that 3,4dihydroxybenzoic acid acts as a indole acetic acid (IAA) synergist by counteracting IAA decarboxylation during IAA-induced growth (Tomaszewski and Thimann, 1966). However, Mucciarelli et al. (2000) suggested the possibility that 3,4-dihydroxybenzoic acid acts directly and independently on cell differentiation. In addition, low concentrations of ferulic acid have been found in cherry cuttings during the time of root formation (Trobec et al., 2005). These results strongly suggest that a relationship exists among red light, phenolic compounds, and root formation. It is likely that red light irradiation inhibited

Table 3. Correlation analysis between phenolic compounds and root growth.

\begin{tabular}{lcc}
\hline & \multicolumn{2}{c}{$\begin{array}{c}\text { Pearson's correlation } \\
\text { coefficient }(r)\end{array}$} \\
\cline { 2 - 3 } & $\begin{array}{c}\text { Rooting } \\
\%\end{array}$ & $\begin{array}{c}\text { No. of } \\
\text { roots }\end{array}$ \\
\hline Phenolic compound & $-0.419^{*}$ & $-0.768^{* *}$ \\
\hline 3,4-Dihydroxybenzoic & & \\
acid & -0.322 & -0.467 \\
Gallic acid & -0.260 & -0.322 \\
Caffeic acid & -0.358 & $-0.732^{* *}$ \\
Ferulic acid &
\end{tabular}

* Correlation is significant at the 0.05 level.

**Correlation is significant at the 0.01 level.

Table 4. Analysis of variance summary for number of roots, number of leaves, leaf dry weight, and shoot dry weight of $P$. cynaroides plantlets.

\begin{tabular}{|c|c|c|c|c|}
\hline Source of variation & $\mathrm{df}$ & Mean square & $\mathrm{F}$ value & $P$ value \\
\hline \multicolumn{5}{|l|}{ Number of roots ${ }^{\mathrm{z}}$} \\
\hline Treatment & 3 & 2.8444 & 13.04 & 0.0006 \\
\hline Error & 11 & 0.2181 & & \\
\hline Corrected total & 14 & & & \\
\hline \multicolumn{5}{|l|}{ Number of leaves } \\
\hline Treatment & 3 & 186.9408 & 31.39 & $<0.0001$ \\
\hline Error & 56 & 5.9547 & & \\
\hline Corrected total & 59 & & & \\
\hline \multicolumn{5}{|l|}{ Leaf dry weight } \\
\hline Treatment & 3 & 1603.2000 & 5.49 & 0.0022 \\
\hline Error & 56 & 292.2167 & & \\
\hline Corrected total & 59 & & & \\
\hline \multicolumn{5}{|l|}{ Shoot dry weight } \\
\hline Treatment & 3 & 294.8167 & 0.79 & 0.5056 \\
\hline Error & 56 & 374.1095 & & \\
\hline Corrected total & 59 & & & \\
\hline
\end{tabular}

${ }^{\mathrm{z}}$ Only includes values from rooted plantlets.

Table 5. Analysis of variance summary of phenolic compounds for P. cynaroides plantlets.

\begin{tabular}{|c|c|c|c|c|}
\hline Source of variation & $\mathrm{df}$ & Mean square & $\mathrm{F}$ value & $P$ value \\
\hline \multicolumn{5}{|c|}{ 3,4-Dihydroxybenzoic acid } \\
\hline Treatment & 3 & 42.2209 & 768.32 & $<0.0001$ \\
\hline Error & 56 & 0.0550 & & \\
\hline Corrected total & 59 & & & \\
\hline \multicolumn{5}{|l|}{ Gallic acid } \\
\hline Treatment & 3 & 184.5979 & 1061.92 & $<0.0001$ \\
\hline Error & 56 & 0.1738 & & \\
\hline Corrected total & 59 & & & \\
\hline \multicolumn{5}{|l|}{ Caffeic acid } \\
\hline Treatment & 3 & 209.5320 & 171.13 & $<0.0001$ \\
\hline Error & 56 & 1.2244 & & \\
\hline Corrected total & 59 & & & \\
\hline \multicolumn{5}{|l|}{ Ferulic acid } \\
\hline Treatment & 3 & 13.8581 & 22.09 & $<0.0001$ \\
\hline Error & 56 & 0.6274 & & \\
\hline Corrected total & 59 & & & \\
\hline
\end{tabular}


the accumulation of 3,4-dihydroxybenzoic acid, gallic acid, and ferulic acid in $P$. cynaroides plantlets, which resulted in the stimulation of adventitious root formation.

The results of the present study also showed that, compared with monochromatic red light, the accumulation of 3,4-dihydroxybenzoic acid, gallic acid, and ferulic acid in $P$. cynaroides plantlets was enhanced by the presence of blue light, whether individually or in combination with red light (red + blue LEDs) (Table 2). This is in agreement with studies that showed that blue light stimulates the biosynthesis of phenolic compounds in plants (Leal-Costa et al., 2010; Meng et al., 2004; Rao and Ravishankar, 2002; Saleh, 2007). Similarly, chlorogenic acid in lettuce seedlings grown under blue-containing LEDs was also higher than those irradiated by red lights (Johkan et al., 2010). Under white fluorescent light, in which a wide range of wavelengths including high levels of blue light were present (Fig. 1), plantlets were found to contain the highest concentrations of all types of phenolic compounds (Table 2). Findings by Shiga et al. (2009) and Shohael et al. (2006) also showed similar trends in terms of total phenolic content under white light. Furthermore, ultraviolet light has been found to induce the production of phenolic compounds (Bakhshi and Arakawa, 2006). Ultraviolet light (peak at $404 \mathrm{~nm}$ ) was detected in the white FLs (Fig. 1) and therefore could be a contributory factor toward the high phenolic compound concentrations. In addition, of all the phenolics, caffeic acid in particular is known as a root growth inhibitor of plants (Barkosky et al., 2000; Batish et al., 2008), and thus, its high concentration under white light is likely to be a factor in the inhibition of root formation of $P$. cynaroides plantlets. Based on these findings, it is probable that the unsuccessful induction of root formation in $P$. cynaroides explants in previous studies, in which white FLs were used as a light source (Thillerot et al., 2006), was the result of the high concentrations of endogenous phenolic compounds.

In conclusion, the highest root and leaf formation was obtained in plantlets irradiated by red LEDs, whereas the lowest concentrations of 3,4-dihydroxybenzoic acid, gallic acid, and ferulic acid were detected in plantlets under the same light source. The relationships among light quality, phenolic compound concentration, and root growth were established. Inverse correlations between phenolic compounds and root growth indicate that low endogenous concentrations of 3,4-dihydroxybenzoic acid and ferulic acid under red LEDs stimulate root formation. Our results suggest that red LEDs are suitable as a light source to promote root and leaf formation in P. cynaroides plantlets.

\section{Literature Cited}

Appelgren, M. 1991. Effects of light quality on stem elongation of Pelargonium in vitro. Sci. Hort. 45:345-351.

Bakhshi, D. and O. Arakawa. 2006. Induction of phenolic compounds biosynthesis with light irradiation in the flesh of red and yellow apples. J. Applied Hort. 8:101-104.
Barkosky, R.R., F.A. Einhellig, and J.L. Butler. 2000. Caffeic acid-induced changes in plantwater relationships and photosynthesis in leafy spurge (Euphorbia esula L.). J. Chem. Ecol. 26:2095-2109.

Batish, D.R., H.P. Singh, S. Kaur, R.K. Kohli, and S.S. Yadav. 2008. Caffeic acid affects early growth, and morphogenetic response of hypocotyl cuttings of mung bean (Phaseolus aureus). J. Plant Physiol. 165:297-305.

Brown, C.S., A.C. Schurger, and J.C. Sager. 1995. Growth and photomorphogenesis of pepper plants under red light-emitting diodes with supplemental blue or far-red lighting. J. Amer. Soc. Hort. Sci. 120:808-813.

Budiarto, K. 2010. Spectral quality affects morphogenesis on Anthurium plantlet during in vitro culture. Agrivita 32:234-240.

Bula, R.J., R.C. Morrow, T.W. Tibbitts, D.J. Barta, R.W. Ingnatius, and T.S. Martin. 1991. Lightemitting diodes as a radiation source for plants. HortScience 26:203-205.

Economou, A.S. and P.E. Read. 1987. Light treatments to improve efficiency of in vitro propagation systems. HortScience 22:751-754.

Goins, G.D., N.C. Yorio, M.M. Sanwo, and C.S. Brown. 1997. Photomorphogenesis, photosynthesis, and seed yield of wheat plants grown under light emitting diodes (LEDs) with or without supplemental blue lighting. J. Expt. Bot. 48:14071413.

Guo, B., Y. Liu, Q. Yan, and C. Liu. 2007. Spectral composition of irradiation regulates the cell growth and flavonoids biosynthesis in callus cultures of Saussurea medusa Maxim. Plant Growth Regulat. 52:259-263.

Hoenecke, M.E., R.J. Bula, and T.W. Tibbitts. 1992. Importance of blue photon levels for lettuce seedlings grown under red-light emitting diodes. HortScience 27:427-430.

Hossen, Z. 2007. Light emitting diodes increase phenolics of buckwheat (Fagopyrum esculentum) sprouts. J. Plant Interact. 2:71-78.

Jao, R.C. and W. Fang. 2004. Effects of frequency and duty ratio on the growth of potato plantlets in vitro using light emitting diodes. Hort Science 39:375-379.

Jao, R.C., C.C. Lai, W. Fang, and S.F. Chang. 2005. Effects of red light on the growth of Zantedeschia plantlets in vitro and tuber formation using light-emitting diodes. HortScience 40:436-438.

Johkan, M., K. Shoji, F. Goto, S. Hashida, and T. Yoshihara. 2010. Blue light-emitting diode light irradiation of seedlings improves seedling quality and growth after transplanting in red leaf lettuce. HortScience 45:1809-1814.

Kim, S., E. Hahn, J. Heo, and K. Paek. 2004. Effects of LEDs on net photosynthetic rate, growth and leaf stomata of chrysanthemum plantlets in vitro. Sci. Hort. 101:143-151.

Kurilčik, A., R. Miklušytė-Čanova, S. Dapkūnienè, S. Žilinskaite, G. Kurilčik, G. Tamulaitis, P. Duchovskis, and A. Žukauskas. 2008. In vitro culture of Chrysanthemum plantlets using lightemitting diodes. Cent. Eur. J. Biol. 3:161-167.

Leal-Costa, M.V., L.B. dos Santos Nascimento, N. dos Santos Moreira, F. Reinert, S. Costa, C.L.S. Lage, and E.S. Tavares. 2010. Influence of blue light on the leaf morphoanatomy of in vitro Kalanchoe pinnata (Lamarck) Persson (Crassulaceae). Microsc. Microanal. 16:576582.

Li, H., Z. Xu, and C. Tang. 2010. Effect of lightemitting diodes on growth and morphogenesis of upland cotton (Gossypium hirutum L.) plantlets in vitro. Plant Cell Tissue Organ Cult. 103: 155-163.
Lian, M.L., H.N. Murthy, and K.Y. Paek. 2002. Effects of light emitting diodes (LEDs) on the in vitro induction and growth of bulblets of Lilium oriental hybrid 'Pesaro'. Sci. Hort. 94: 365-370.

Littlejohn, G.M., G.C. van den Berg, and P. Matlhoahela. 2003. Within plant distribution of macronutrients in Protea 'Cardinal'. Acta Hort. 602:93-98.

Malan, D.G. 1992. Propagation of Proteaceae. Acta Hort. 316:27-35.

Meng, X., T. Xing, and X. Wang. 2004. The role of light in the regulation of anthocyanin accumulation in Gerbera hybrida. Plant Growth Regulat. 44:243-250.

Mucciarelli, M., S. Scannerini, M. Gallino, and M. Maffei. 2000. Effects of 3,4-dihydroxybenzoic acid on tobacco (Nicotiana tabacum L.) cultured in vitro. Growth regulation in callus and organ cultures. Plant Biosyst. 134:185-192.

Murashige, T. and F. Skoog. 1962. A revised medium for rapid growth and bioassays with tobacco tissue cultures. Physiol. Plant. 15:473497.

Nhut, D.T., L.T.A. Hong, H. Watanabe, M. Goi, and M. Tanaka. 2002. Growth of banana plantlets cultured in vitro under red and blue light-emitting diode (LED) irradiation source. Acta Hort. 575:117-124.

Nhut, D.T. and N.B. Nam. 2010. Light-emitting diodes (LEDs): An artificial lighting source for biological studies. IFMBE Proc. 27:134139.

Nhut, D.T., T. Takamura, H. Watanabe, K. Okamoto, and M. Tanaka. 2003. Responses of strawberry plantlets cultured in vitro under superbright red and blue light-emitting diodes (LEDs). Plant Cell Tissue Organ Cult. 73:43-52.

Okamoto, K., T. Yanagi, and S. Kondo. 1997. Growth and morphogenesis of lettuce seedlings raised under different combinations of red and blue light. Acta Hort. 435:149-157.

Okamoto, K., T. Yanagi, and S. Takita. 1996 Development of plant growth apparatus using blue and red LED as artificial light source. Acta Hort. 440:111-116.

Patterson-Jones, C. 2000. The Protea family in Southern Africa. Struik Publishers, Cape Town.

Poudel, P.R., I. Kataoko, and R. Mochioka. 2008. Effect of red- and blue-light-emitting diode on growth and morphogenesis of grapes. Plant Cell Tissue Organ Cult. 92:147-153.

Rao, S.R. and G.A. Ravishankar. 2002. Plant cell cultures: Chemical factories of secondary metabolites. Biotechnol. Adv. 20:101-153.

Saleh, A.A.H. 2007. Influence of $U_{\mathrm{A}+\mathrm{B}}$ radiation and heavy metals on growth, some metabolic activities and antioxidant system in pea (Pisum sativum) plant. Amer. J. Plant Physiol. 2:139154.

SAS Institute Inc. 1996. The SAS system for Windows. Cary, NC.

Shiga, T., K. Shoji, H. Shimasa, S. Hashida, F. Goto, and T. Yoshihara. 2009. Effect of light quality on rosmarinic acid content and antioxidant activity of sweet basil, Ocimum basilicum L. Plant Biotechnol. 26:255-259.

Shin, K.S., H.N. Murthy, J.W. Heo, E.J. Hahn, and K.Y. Paek. 2008. The effect of light quality on the growth and development of in vitro cultured Doritaenopsis plants. Acta Physiol. Plant. 30:339 343.

Shohael, A.M., M.B. Ali, K.W. Yu, E.J. Hahn, R. Islam, and K.Y. Paek. 2006. Effect of light on oxidative stress, secondary metabolites and induction of antioxidant enzymes in Eleutherococcus senticosus somatic embryos in bioreactor. Process Biochem. 41:1179-1185. 
Shoji, K., E. Goto, S. Hashida, F. Goto, and T. Yoshihara. 2011. Effect of light quality on the polyphenol content and antioxidant activity of Sweet basil (Ocimum basilicum L.). Acta Hort. 907:95-100.

Taiz, L. and E. Zeiger. 1991. Plant physiology. 3rd Ed. Benjamin/Cummings Publishing Co., New York, NY. p. 179-264.

Thillerot, M., F. Choix, A. Poupet, and M. Montarone. 2006. Micropropagation of Leucospermum 'High Gold' and three cultivars of Protea. Acta Hort. 716:17-24.

Tomaszewski, M. and K.V. Thimann. 1966. Interactions of phenolic acids, metallic ions and chelating agents on auxin-induced growth. Plant Physiol. 41:1443-1454.

Trobec, M., F. Stampar, R. Veberic, and G. Osterc. 2005. Fluctuations of different endogenous phenolic compounds and cinnamic acid in the first days of the rooting process of cherry rootstock 'GiSelA 5' leafy cuttings. J. Plant Physiol. 162:589-597.

Tso, T.C., M.J. Kasperbauer, and T.P. Sorokin. 1970. Effect of photoperiod and end-of-day light quality on alkaloids and phenolic compounds of tobacco. Plant Physiol. 45:330-333.

Urbonaviciute, A., G. Samuoliene, A. Brazaityte, P. Duchovskis, V. Ruzgas, and A. Zukauskas. 2009a. The effect of variety and lighting quality on wheatgrass antioxidant properties. ZemdirbysteAgriculture 96:119-128.

Urbonaviciute, A., G. Samuoliene, A. Brazaityte, V. Ruzgas, G. Šabajeviene, K. Šliogeryte, J. Sakalauskaite, P. Duchovskis, and A. Žukauskas. $2009 \mathrm{~b}$. The effect of light quality on the antioxidative properties of green barley leaves. Sci. Works Lith. Inst. Hort. Lith. Uni. Agric. 28: 153-161.
Wu, H.C. and E.S. du Toit. 2004. Reducing oxidative browning during in vitro establishment of Protea cynaroides. Sci. Hort. 100:355358.

Wu, H.C., E.S. du Toit, and C.F. Reinhardt. 2007a. A protocol for direct somatic embryogenesis of Protea cynaroides L. using zygotic embryos and cotyledon tissues. Plant Cell Tissue Organ Cult. 89:217-224.

Wu, H.C., E.S. du Toit, C.F. Reinhardt, A.M Rimando, F. van der Kooy, and J.J.M. Meyer. 2007b. The phenolic, 3,4-dihydroxybenzoic acid, is an endogenous regulator of rooting in Protea cynaroides. Plant Growth Regulat. 52:207215.

Yanagi, T. and K. Okamoto. 1997. Utilization of super-bright light emitting diodes as an artificial light source for plant growth. Acta Hort. 418:223-228 